Hanif M. Ladak, Willem F. Decraemer, Joris J. J. Dirckx, \& W. Robert J. Funnell

\title{
Response of the cat eardrum to static pressures: Mobile versus immobile malleus
}

Published in:

Journal of the Acoustical Society of America, 116, 3008 (2004)

Copyright (2004) Acoustical Society of America. This article may be downloaded for personal use only. Any other use requires prior permission of the author and the Acoustical Society of America.

doi:10.1121/1.1802673

http://scitation.aip.org/content/asa/journal/jasa/116/5/10.1121/1.1802673 


\title{
Response of the cat eardrum to static pressures: Mobile versus immobile malleus
}

\author{
Hanif M. Ladak ${ }^{\text {a) }}$ \\ Department of BioMedical Engineering, McGill University, Montréal H3A 2B4, Canada \\ Willem F. Decraemer and Joris J. J. Dirckx \\ Laboratory of BioMedical Physics, University of Antwerp, Antwerpen B-2020, Belgium \\ W. Robert J. Funnell ${ }^{\text {b) }}$ \\ Departments of BioMedical Engineering and Otolaryngology, McGill University, \\ Montréal H3A 2B4, Canada
}

(Received 18 February 2004; revised 9 August 2004; accepted 12 August 2004)

\begin{abstract}
A phase-shift shadow moiré interferometer was used to measure the shape of the cat eardrum with a normal mobile malleus and with an immobile malleus as it was cyclically loaded with static middle-ear pressures up to $\pm 2.2 \mathrm{kPa}$. The shape was monitored throughout the loading and unloading phases, and three complete cycles were observed. The mobile-manubrium measurements were made in five ears. In three ears, the malleus was then immobilized with a drop of glue placed on the head of the malleus. Eardrum displacements were calculated by subtracting shape images pixel by pixel. The measurements are presented in the form of gray-level full-field shape and displacement images, of displacement profiles, and of pressure-displacement curves for selected points. Displacement patterns with a mobile malleus show that pars-tensa displacements are larger than manubrial displacements, with the maximum pars-tensa displacement occurring in the posterior region in all cats except one. Displacements vary from cycle to cycle and display hysteresis. For both the mobile-malleus and immobile-malleus cases, the eardrum response is nonlinear. The response is asymmetric, with lateral displacements being larger than medial displacements. With a mobile malleus, manubrial displacements exhibit more pronounced asymmetry than do pars-tensa displacements. (C) 2004 Acoustical Society of America. [DOI: 10.1121/1.1802673]
\end{abstract}

PACS numbers: 43.64.Ha [BLM]

Pages: $3008-3021$

\section{INTRODUCTION}

Static pressure differences across the eardrum occur in everyday life. They can, for example, be caused by atmospheric pressure changes felt in an elevator or airplane before the Eustachian tube opens to equilibrate the middle ear to ambient pressure. It is a common experience that, when the Eustachian tube function is impaired (e.g., due to a cold), these pressure differences increase the hearing threshold by decreasing the transmission of sound energy across the middle ear. Since the eardrum is a significant determinant of the transmission characteristics of the middle ear, it is important to understand its response to large static pressures.

Most experimental work on the mechanical behavior of the eardrum concentrates on its dynamic response. In contrast, very little work has focused on its static response, although because of technological limitations early investigators tried to elucidate the acoustical transmission characteristics of the eardrum using static pressures (e.g., Kessel, 1874; Dahmann, 1930). The first full-field quantitative measurements of static eardrum displacement patterns (Dirckx, 1990; Dirckx and Decraemer, 1991; Decraemer et al., 1991) were done using a phase-shift shadow moiré

\footnotetext{
${ }^{a)}$ Present address: Department of Medical Biophysics, Medical Sciences Building, The University of Western Ontario, London N6A 5C1, Canada. Electronic mail: hladak@uwo.ca

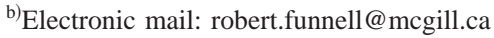

interferometer. With this noncontacting optical device, the shape of a human cadaver eardrum was measured in response to a sequence of positive and negative static middleear pressures. Since then, moiré interferometry has also been used to measure the static mechanical response of the cat eardrum (Decraemer and Dirckx, 1991; Stoffels, 1993; Funnell and Decraemer, 1996) and of the gerbil eardrum (von Unge et al., 1993, 1999; Dirckx et al., 1998; Dirckx and Decraemer, 2001). Parnes et al. (1996) used electronic specklepattern interferometry to measure the response of the eardrum to static pressures, and Vorwerk et al. (1998) recorded the motion of the human eardrum in response to quasistatic pressures using an endoscope and a video-recording system.

All of the above experiments were performed with an intact middle ear; however, for purposes of modeling static eardrum response, it is also useful to study its mechanical response in isolation from middle-ear structures such as the ossicles and ligaments, by immobilizing the ossicles. Quantitative data on static eardrum displacement patterns with an immobile malleus would simplify refinement of existing computer models of the eardrum. In many such models (e.g., Funnell and Laszlo, 1978), assumptions are made about the material properties of the eardrum. For instance, the Young's modulus, or stiffness, of the eardrum is assumed to be constant over its surface. With the availability of experimental data, one could use numerical optimization techniques to determine distributions of material properties over the entire 


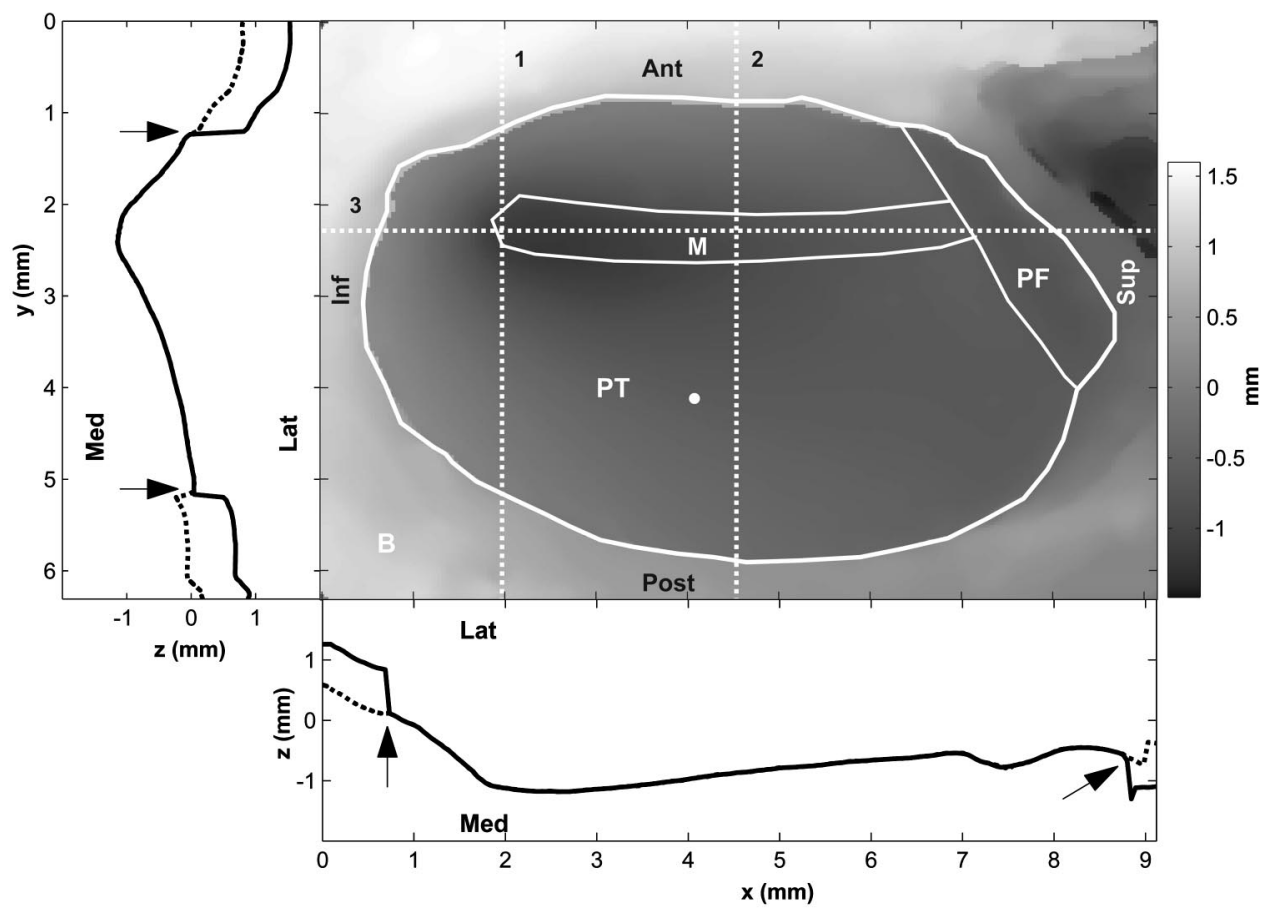

FIG. 1. Gray-level image of resting shape of eardrum of cat MY1216L. The thick white line encloses the visible portion of the eardrum. The pars tensa (PT), manubrium (M), and pars flaccida (PF) are outlined, and the surrounding bony tissue is indicated (B). The dot indicates a point on the pars tensa for which pressure-displacement curves are later plotted. The anterior (Ant), posterior (Post), inferior (Inf), and superior (Sup) directions are also indicated. These anatomical directions are approximate. The cat eardrum is actually tilted, so the pars flaccida is both posterior and superior (dorsal) and the manubrium runs in the antero-inferior to postero-superior direction. The bottom panel shows a horizontal profile through the umbo, and the leftmost panel shows a vertical profile through the umbo. The locations of the profiles are shown on the image by dotted lines 1 and 3 ; line 2 is referred to later in the text. The umbo is located at the intersection of lines 1 and 3. The medial (Med) and lateral (Lat) directions are indicated for the profiles. Solid profiles are after phase unwrapping with the coarse grating to determine the height of true jumps (see Sec. II E), whereas dotted profiles are after phase unwrapping but without using the coarse grating. The arrows indicate the locations of true jumps caused by overhanging ear-canal tissue.

surface of the eardrum. This would involve systematically adjusting the material properties until predicted displacement patterns match measured ones. Immobilizing the malleus would allow one to perform the optimization without having to take into account the additional complexity of the mechanical loading effects of the ossicular chain on the eardrum. Indeed, computer simulations of the eardrum with an immobile malleus have previously been used to study the effects of individual eardrum shape differences on the eardrum mechanical response (Funnell and Decraemer, 1996). The dynamic response of the eardrum has been studied experimentally under this condition in order to understand the effects of otosclerosis (Margolis et al., 1978; Naito, 1990; von Unge et al., 1991), but no such experiments have been reported for the static response.

The objective of this work was to measure the response of the cat eardrum to a sequence of static pressures before and after immobilizing the malleus. Complete loading/ unloading cycles were measured repeatedly under both conditions.

\section{METHODS}

\section{A. Apparatus}

The shape of the eardrum is measured using phase-shift shadow moiré interferometry. In the moire method, the shadow of a grating consisting of parallel lines is cast onto the surface to be measured. The shadow is a set of deformed lines and forms a moiré interference pattern when viewed through the original grating. The moiré interference images are recorded using a CCD camera and frame store. Four phase-shifted images are obtained by translating the object being measured away from the grating. The four images are combined mathematically, pixel by pixel, to form a single shape image in which the value of each pixel is proportional to the $z$ coordinate of a point, and the column and row numbers of the pixel are proportional to the $x$ and $y$ coordinates, respectively. Mathematical details of the method can be found elsewhere (Dirckx et al., 1988). The phase-shift moiré apparatus used in this work has been described previously (Dirckx and Decraemer, 1989). The depth-measuring resolution of the interferometer is $20 \mu \mathrm{m}$, and the spacings between pixels along the $x$ and $y$ axes are 46 and $32 \mu \mathrm{m}$, respectively.

As an example, Fig. 1 shows a gray-level image representing the "resting shape" of the eardrum of cat MY1216L. The resting shape is defined as the shape measured at the very start of a set of measurements with no pressure being applied. The gray levels in this image vary from black (points furthest from the reader) to white (points closest to the reader). The darker central region enclosed by the thick white line is the eardrum, whereas the lighter region surrounding it (B) represents the bony part of the ear canal. The areas of the eardrum corresponding to the pars tensa (PT), pars flaccida (PF), and manubrium (M) are roughly outlined by white lines. The large black area to the right of the pars 
flaccida is a region of bone that is far from the reference plane of the moire interferometer, and therefore not imaged correctly. A vertical profile through the umbo is shown to the left of the image, and a horizontal profile through the manubrium is shown at the bottom. The locations of the profiles are shown on the image by dotted lines 1 and 3 . The umbo is located at the intersection of these two lines.

Note that there is no specific relationship between the columns and rows in the image and the anatomy. However, in all of the images acquired in this work, the manubrium was generally oriented to be approximately parallel to the $x$ axis, i.e., it was parallel to the rows in the image.

\section{B. Specimen preparation}

Measurements were made on five fresh temporal bones obtained from adult cats (MY0923R, MY1216L, MY1630L, MY1721L, MY2626L), which had been used for purposes unrelated to the auditory system. The cats were sacrificed with an intracardiac injection of pentobarbital $\mathrm{Na}$ solution (60 mg/kg body weight). The temporal bones were removed from the cats approximately 15-30 min post mortem. When the temporal bones were removed, the auditory and facial nerves were cut. The bulla and petrous bones were intact. No holes were introduced into the middle ear, as evidenced by the ability to maintain a constant pressure in the middle-ear space during the measurement procedure, which is described in the next section.

In order to provide a good view of the eardrum, the ear canal is resected to within $1 \mathrm{~mm}$ of the eardrum. Since the moiré technique requires a diffusely reflecting surface, the lateral surface of the eardrum is coated with a thin uniform layer of drawing ink (Pelican Drawing Ink A, 18 White). This ink does not significantly affect the mechanical response of the eardrum (Dirckx and Decraemer, 1997). In order to apply pressures to the middle-ear cavities, a small hole is drilled in the middle-ear wall, and a plastic tube for applying pressures is glued to the hole using Loctite 406 cyanoacrylate, which provides an airtight connection. The specimen is then placed in the moire apparatus. Total preparation time is about 2.5 to $3 \mathrm{~h}$ for a single specimen.

\section{Measurement procedure}

Three cycles of pressure are applied to the eardrum. Each cycle starts from rest (i.e., zero pressure in the middleear cavities) and involves loading the eardrum by applying positive middle-ear pressures in the order $0.1,0.2,0.4,0.7$, $1.1,1.6$, and $2.2 \mathrm{kPa}$, then unloading back to $0 \mathrm{~Pa}$ in the reverse order. The eardrum is then loaded by applying negative middle-ear pressures in the same order and unloaded in the reverse order. The pressure values used in this experiment cover the pressure range normally encountered in everyday life. We shall see that the displacement of the eardrum levels off at the extreme applied pressures, so that the entire displacement range is covered.

At each step in a cycle, the pressure is maintained at a constant value, and eardrum shape is measured using the moiré apparatus with a grating having a pitch of 4 lines $/ \mathrm{mm}$. A single shape measurement, including time to save the im- age to a hard disk, takes $45 \mathrm{~s}$. A shape measurement is made $5 \mathrm{~s}$ after the pressure is adjusted to a new level. This ensures that both pressure and eardrum shape have stabilized. Once the eardrum shape is measured at a given level, the pressure is immediately changed to the next level. All three cycles are measured in immediate succession with no pauses in between. Once all three cycles have been measured, the grating is replaced by a coarser one having a pitch of 0.8 lines $/ \mathrm{mm}$, and a single unpressurized shape measurement is made. As explained in Sec. IIE, the last measurement with the coarse grating is used as a guide for "phase unwrapping." The time required to measure all three cycles and the shape with the coarser grating is about $1.25 \mathrm{~h}$. A total of 86 shape measurements is made: 85 using the fine grating, and one using the coarse grating.

\section{Mallear fixation}

For three of the five specimens, after measurements had been made with a mobile malleus, the specimen was removed from the apparatus and the malleus was fixed to the middle-ear wall. (In one of the five cats, the malleus could not be fixed, and one other was used to investigate the effects of measurement time as discussed below.) A small hole is drilled in the middle-ear wall superior to the pars flaccida. In this region, the mallear neck and head are separated from the adjacent middle-ear wall by a small gap. Once the malleus is exposed, a small drop of glue (Loctite 406 cyanoacrylate) is placed on its head to fix the malleus to the intact portion of the middle-ear wall. The glue is placed on the mallear head when it is somewhat viscous so that it does not run onto the eardrum. This particular glue cures within seconds, which is much less than the time required to place the specimen back in the moire interferometer. Once the glue is completely dry, the hole is sealed airtight with dental cement. When the middle ear is exposed to air, as in this procedure for fixing the malleus, the mucosal lining can dry out (Tonndorf and Khanna, 1972). To prevent desiccation of the lining while the malleus is being fixed, the above manipulations are done in the mist of a humidifier (Defensor 505). The mist was used to keep the outer surface of the bone moist and did not enter the middle-ear cavity. At the output of the humidifier, the mist formed a cloud with a diameter of approximately $30 \mathrm{~cm}$, and the temporal bone was held in the middle of this cloud with the eardrum facing away from the output of the humidifier.

Once the malleus is fixed, the specimen is remounted in the moiré apparatus, and its response to static pressures is measured again as outlined in the previous section. The total time to fix the malleus and remount the specimen is 1.5 to $2 \mathrm{~h}$. No leaks were detected around the sealed hole during subsequent pressurized shape measurements.

In one of the five specimens (MY1721L), the malleus was not fixed. Instead, after the first set of shape measurements was made, the specimen was left in the apparatus for $2 \mathrm{~h}$, and shape measurements were then repeated. This specimen served as a control to assess changes in specimen shape and response with time. 


\section{E. Phase unwrapping}

The $z$ values at each pixel in a moiré shape image are computed as phase angles derived from the four phaseshifted moire interference images, and the result is therefore "wrapped" into the range 0 to $\lambda$, where $\lambda$ is the size of the ambiguities that must be unwrapped. The value of $\lambda$ is obtained by calibration of the moire interferometer (Dirckx and Decraemer, 1990). The $z$ coordinates in the wrapped shape image must be "unwrapped" to produce a shape image such as the one in Fig. 1. The unwrapping is done by adding multiples of $\lambda$ where required. For the measurements reported here with the fine grating of 4 lines $/ \mathrm{mm}, \lambda$ $=0.74 \mathrm{~mm}$. A two-step procedure is used to unwrap the wrapped images measured with the fine grating. First each wrapped image is unwrapped using an automatic method (Dirckx et al., 1988; Dirckx, 1990; Funnell and Decraemer, 1996). The procedure involves first unwrapping the central column of the image; profile 2 in Fig. 1 indicates the location of the central column. The column is scanned pixel by pixel from its center to the top and then from the center to the bottom. During each scan, a running offset is added to each pixel. The offset is incremented or decremented by $\lambda$ whenever the difference between two successive pixels exceeds a threshold value of $\pm \lambda / 2$. Once the central column is unwrapped, each row is unwrapped in turn using the same procedure: each row is scanned first from the center to the left, then from the center to the right, and a running offset is added.

The above algorithm works well for smooth surfaces, but problems arise when there are true abrupt jumps in the $z$ coordinates, as are present in the eardrum-shape images where the bony ear-canal tissue overhangs the periphery of the eardrum. The height of each jump is wrapped into the range 0 to $\lambda$ It is not clear from examining the data how many multiples of $\lambda$ need to be added to correctly reconstruct a jump. Although interest here is focused on the eardrum itself and not on the bony region surrounding it, it is necessary to reconstruct the height of this region properly for better visualization and, more importantly, for correct registration, which is described in the following section. Therefore, the second step in the unwrapping procedure involves correcting the heights of true jumps in unwrapped images measured using the fine grating. Abrupt height variations can be measured correctly if a larger value of $\lambda$ is used so that all surface-height variations remain within the range 0 to $\lambda$ (Zhao et al., 1994). Since $\lambda$ is proportional to the period of the grating, a coarser grating will result in a larger value of $\lambda$, denoted by $\lambda_{c}$. A grating with 0.8 lines $/ \mathrm{mm}$ is therefore used to obtain a supplementary eardrum shape image at zero pressure (corresponding to the 86th measurement). For this grating, $\lambda_{c}$ is $3.7 \mathrm{~mm}$. Since all points on the eardrum are less than $3.5 \mathrm{~mm}$ away from the grating, images measured with this grating need not be unwrapped; moreover, the heights of true jumps are correctly determined since they are all less than $\lambda_{c}$. Given that the resolution obtained with the coarse grating is poorer than that obtained with the fine grating, the coarse grating cannot be used to make all shape measurements, especially in response to pressures where the induced shape changes-calculated as differences between shape images-are subtle. The measurement with the coarse grating simply serves as a guide for correcting unwrapped images measured with the fine grating. The image measured with the coarse grating is used to correct the first image measured with the fine grating by pairwise matching of the images: image 1 is compared with the one measured with the coarse grating pixel by pixel and integer multiples of $\lambda$ are added to the former image to minimize the differences between the two images. Once image 1 is corrected, it is used to correct image 2 . Once image 2 is corrected, it is used to correct image 3 , and so on until all 85 images measured with the fine grating have been corrected. The images are corrected in this order since the $z$-coordinate difference between two images with different pressures may well be greater than $\lambda$ unless the pressures are close together.

The dotted curves in Fig. 1 are vertical and horizontal profiles, after automatic unwrapping but before correction using the supplementary coarse image; the arrows indicate places where there are true jumps in the data that are not unwrapped properly. The solid curve is the same profile after pairwise matching with the image measured using the coarse grating: the heights of the jumps are unwrapped properly.

\section{F. Data registration}

As explained above, after the eardrum response is measured with a mobile malleus, the specimen is removed from the apparatus, the malleus is fixed, and the specimen is placed back in the apparatus for further measurements. When the specimen is replaced, its orientation with respect to the interferometer grating is usually not quite the same as before it was removed. The change in orientation involves a small rigid-body translation and rotation of the specimen with respect to the grating. To compare shape measurements made after mallear fixation with those made with a mobile malleus, the measured surfaces must be aligned or "registered" with respect to one another.

To register the data, a rigid-body transformation must be found which aligns the two data sets. While the eardrum may change shape, the bony region surrounding the eardrum does not change shape with pressure or time and can be used to find the transformation. The Iterative Closest Point (ICP) algorithm by Besl and McKay (1992) is used to calculate the transformation. Given an initial estimate of the rigid-body transformation, the algorithm iteratively refines it until points on one surface (here, the bony region in the fixed-malleus data set) are aligned with their closest counterparts on a reference surface (the bony region in the data set with a mobile malleus). The iterations stop when the mean-square distance between corresponding points on the two surfaces does not change significantly between iterations. The advantage of the ICP algorithm is that it does not require one to identify corresponding landmarks on both surfaces, which is difficult to do very accurately; however, it is necessary to provide an initial estimate of the transformation.

A simple technique is used to find an initial transformation. Features are roughly identified on the bone in the shape image with a mobile malleus, and corresponding features are identified in the image with a fixed malleus. The bone surrounding the eardrum contains some features (e.g., sharp cor- 


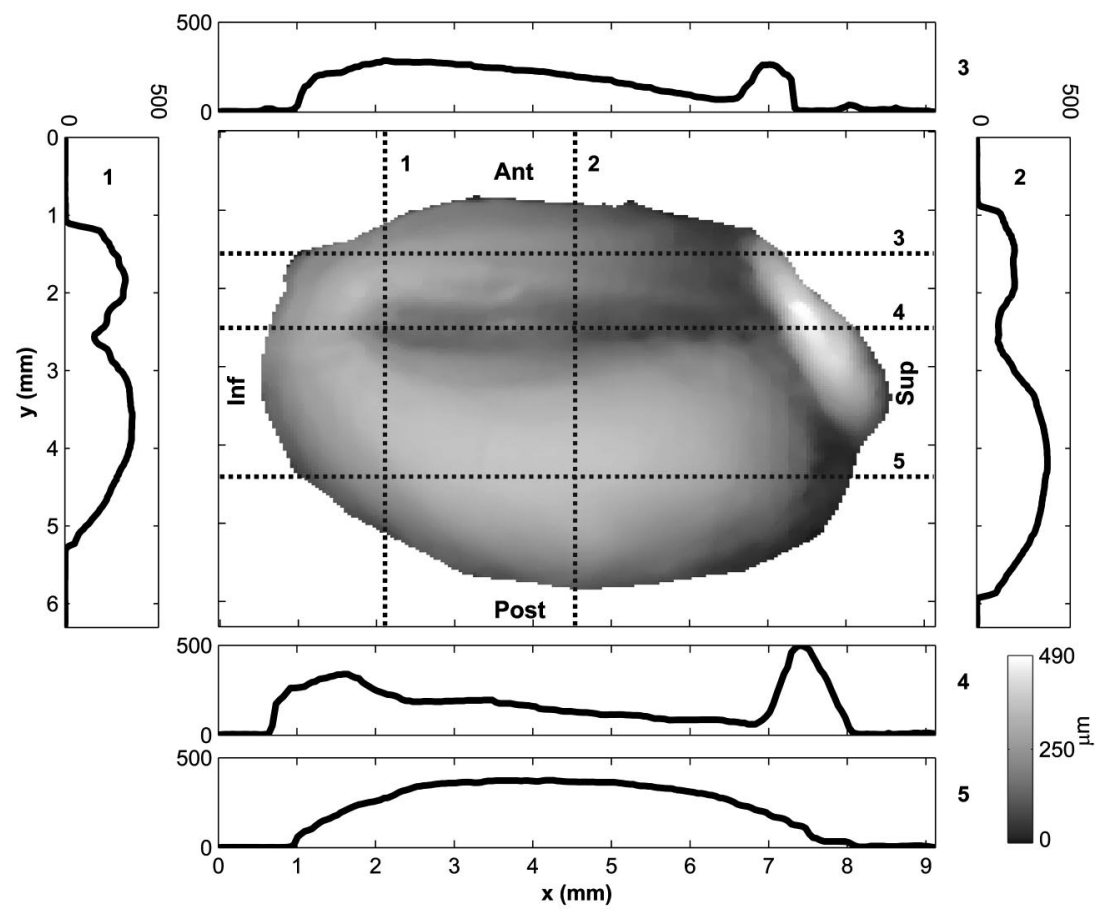

FIG. 2. Gray-level displacement image and profiles for cat MY1216L measured at a pressure of $+2.2 \mathrm{kPa}$ during the first cycle. The gray levels in the image are proportional to displacement magnitude with white corresponding to the largest displacement $(490 \mu \mathrm{m}$, occurring in the pars flaccida) and black to the smallest (0 $\mu \mathrm{m})$. Dotted lines indicate where the profiles are extracted from. Profile 1 was taken through the umbo; 2 was extracted halfway along the manubrium and perpendicular to it; 3 was taken midway in the anterior pars tensa; 4 passes through the length of the manubrium; and 5 passes through the point of maximal parstensa displacement. Displacements indicated on the profiles are in $\mu \mathrm{m}$.

ners formed by the resection process) that can be identified in both images. The features do not represent the same anatomical landmark from one cat to the next, but they are points that are easy to identify in two different shape images of the same eardrum. The correspondences are not exact, but are good enough for an initial estimate. Generally about 10-15 points are used. Once the points are identified, the rigid-body transformation that maps points in the fixed-malleus image to points in the mobile-malleus image is estimated by minimizing the mean-square distance between the two sets of points. The minimization technique described by Horn (1987) is used because it is efficient, requiring no iterations. Since the correspondences are not exact, the transformation is not very good and needs to be refined using the ICP algorithm described above.

The root-mean-square difference in $z$ coordinates of the bony region, after registration of the fixed-malleus data to the mobile-malleus data, was within $30 \mu \mathrm{m}$, indicating good registration.

\section{RESULTS}

\section{A. Mobile malleus}

\section{Full-field displacement patterns}

Changes in eardrum shape produced by the application of pressure are subtle and difficult to see in gray-level representations of the pressurized shape data. To emphasize these changes, full-field displacement patterns are presented in this section, and profiles through the shape data are presented in the next section. The displacement field for a pressure $p$, denoted as $\Delta z_{p}(x, y)$, is defined as $\Delta z_{p}(x, y)$ $=z_{p}(x, y)-z_{0}(x, y)$, where $z_{p}(x, y)$ is the shape measured at pressure $p$ and $z_{0}(x, y)$ is the resting shape measured at the very start of the experiment.

Figure 2 shows a gray-level image of the displacement field for cat MY1216L for the largest positive pressure used in this study $(+2.2 \mathrm{kPa})$ during the first cycle of pressurization. The gray levels in the image are proportional to displacement magnitude, with white corresponding to the largest displacement (490 $\mu \mathrm{m}$, occurring in the pars flaccida) and black to the smallest $(0 \mu \mathrm{m})$. Also shown are profiles through the displacement field; the locations of the profiles are shown on the image by dotted lines. Displacements of the pars tensa, both anterior and posterior, are larger than manubrial displacements; this is best seen in profiles 1 and 2 . The posterior pars tensa displaces more than the anterior pars tensa. As seen in profile 5, a broad maximum occurs in the posterior pars tensa. The largest pars-tensa displacement is $380 \mu \mathrm{m}$. The manubrium appears to be rigid, with manubrial displacements (profile 4) increasing approximately linearly from the superior end to the inferior end. The displacement of the umbo is $250 \mu \mathrm{m}$. As indicated by profiles 3 and 4, the pars flaccida bulges considerably, having a maximum displacement of $490 \mu \mathrm{m}$. The ends of some of the profiles stop abruptly as the periphery of the eardrum is obscured by overhanging tissue.

Figure 3 shows iso-amplitude displacement contours at $+2.2 \mathrm{kPa}$ for all five cats. The difference in amplitude between adjacent contours is $50 \mu \mathrm{m}$. As a guide, some of the contours are labeled. The thick black line represents the outline of the visible portion of the eardrum. Patterns for the other cats are qualitatively similar to that for cat MY1216L, but there are some differences, especially in displacement magnitudes. For cats MY1630L, MY2626L, and MY1721L, pars-flaccida displacements are not as large as pars-tensa displacements. In cat MY0923R, the largest pars-tensa displacement occurs in the anterior region, as opposed to the posterior region as in the other cats. Visual inspection of this specimen did not reveal any pathology which could have resulted in localized differences in compliance.

Displacement patterns for other pressures and cycles are qualitatively similar. For extreme negative pressures, how- 

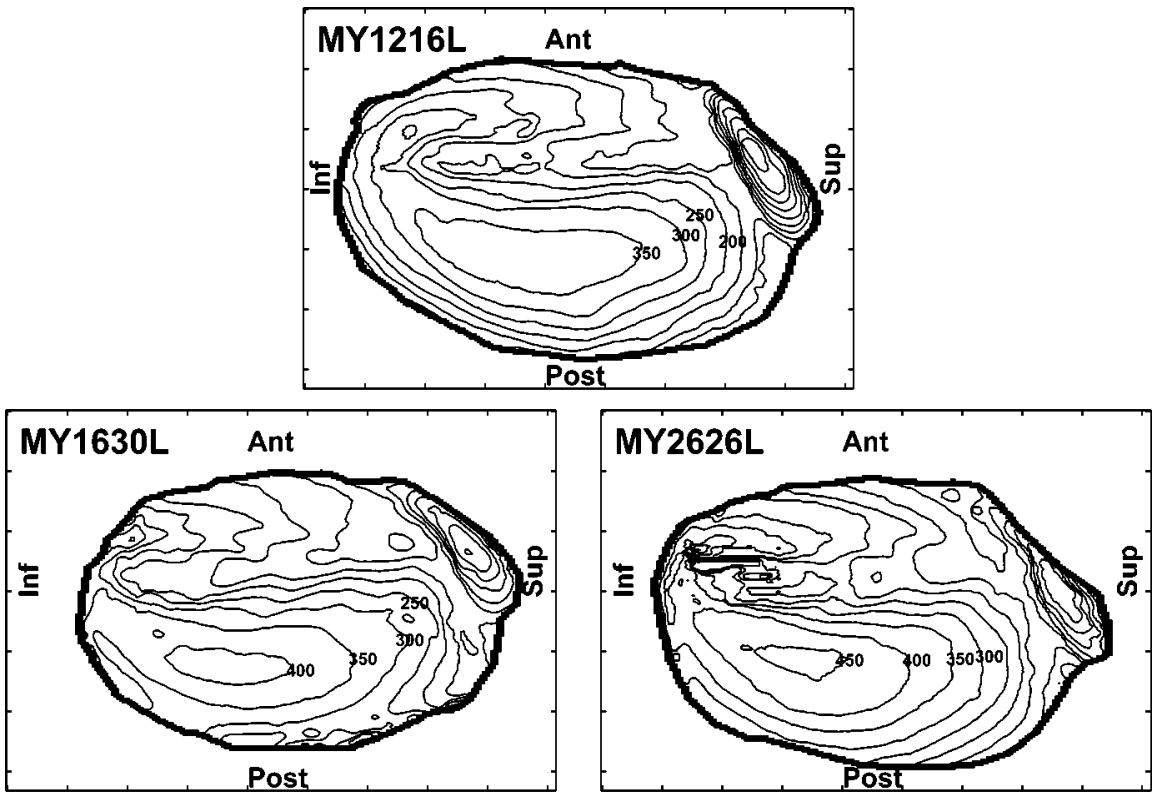

FIG. 3. Iso-amplitude displacement contours for all cats used in this study, measured at a pressure of $+2.2 \mathrm{kPa}$ during the first cycle. Displacements are in $\mu \mathrm{m}$, and adjacent contours are $50 \mu \mathrm{m}$ apart. Note that in cat MY0923R measurements were made on the right ear instead of the left ear as in the other cats. To facilitate comparison of MY0923R with the other cats, the image of the eardrum was mirrored to look like the others.
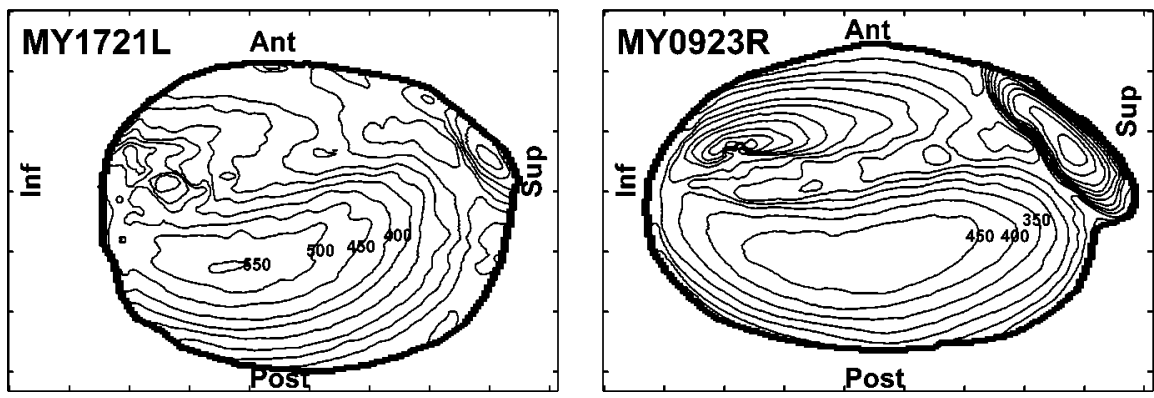

ever, the location of the maximum pars-tensa displacement is slightly inferior to that for positive pressures.

\section{Pressurized shape profiles}

Changes in eardrum curvature are best shown by plotting profiles through the pressurized shape data. Figure 4 shows vertical profiles through the pressurized shape data for cat MY1216L. The profiles are taken at the same location as profile 2 in Fig. 1. Panel (a) shows the response to positive pressures during loading (i.e., while the pressure is increased from $0 \mathrm{~Pa}$ to $+2.2 \mathrm{kPa}$ ), whereas panel (b) shows the response to negative pressures, also during loading (i.e., the (a)

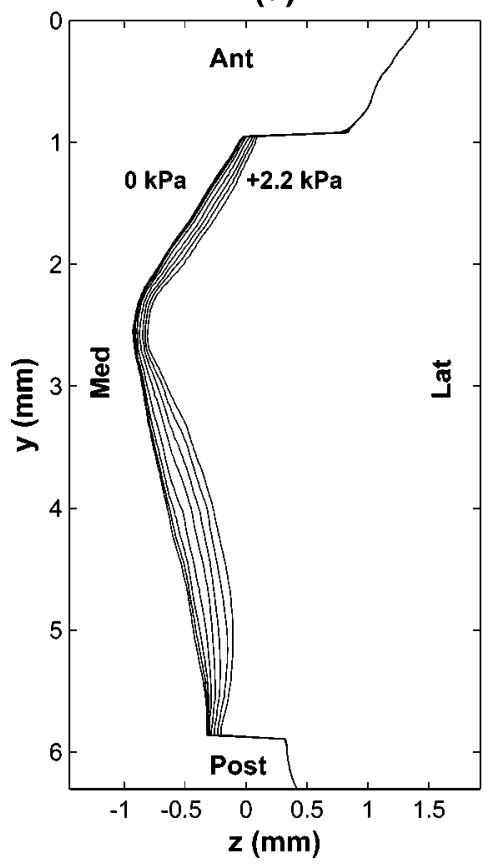

(b)

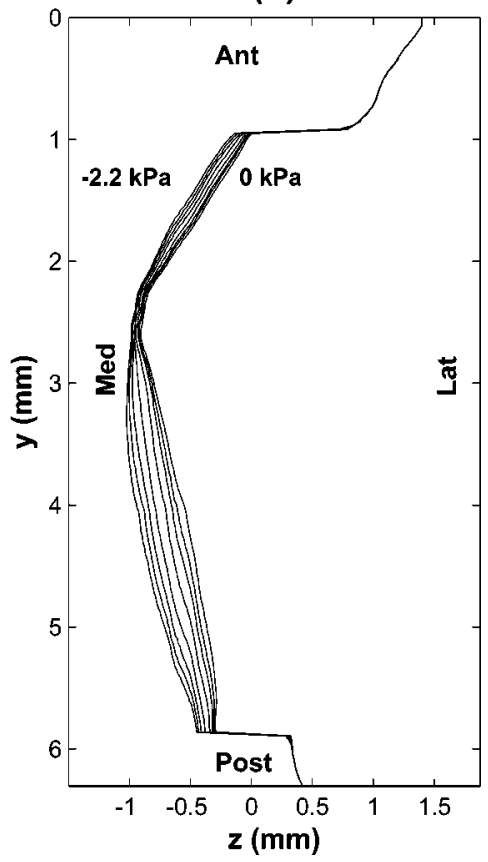

FIG. 4. Vertical profiles through pressurized shape data for cat MY1216L, where $z$ is the height of each point on the eardrum relative to the tympanic ring. The profiles are taken through a point halfway along the manubrium and perpendicular to it. (a) For first cycle while sequentially loading from $0 \mathrm{kPa}$ (leftmost profile) to $+0.1,+0.2,+0.4,+0.7,+1.1,+1.6$, and finally $+2.2 \mathrm{kPa}$. (b) For first cycle while loading from $0 \mathrm{kPa}$ (rightmost profile) to $-0.1,-0.2,-0.4,-0.7,-1.1$, -1.6 , and $-2.2 \mathrm{kPa}$. 
(a)

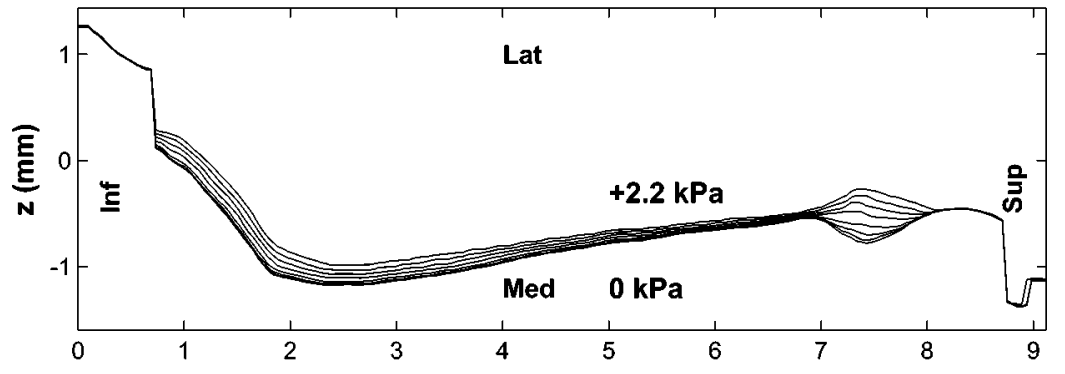

(b)

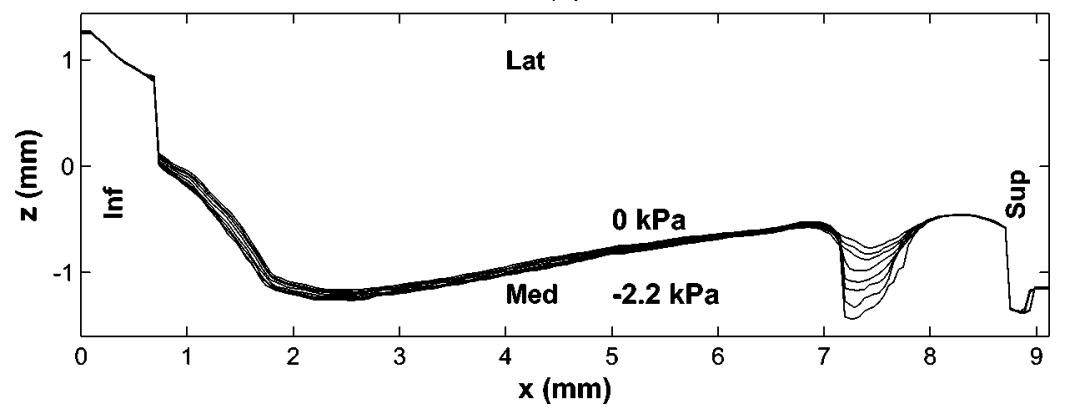

FIG. 5. Horizontal profiles through pressurized shape data for cat MY1216L. The profiles are taken through the manubrium. (a) For first cycle while loading from 0 to $+2.2 \mathrm{kPa}$. (b) For first cycle while loading from 0 to $-2.2 \mathrm{kPa}$. pressure is changed from $0 \mathrm{~Pa}$ to $-2.2 \mathrm{kPa}$ ). The displacements do not reach zero at the anterior and posterior ends because the periphery of the eardrum is hidden beneath overhanging tissue.

The description of eardrum convexity and concavity in this paragraph refers to the sections of the eardrum shape profile anterior and posterior to the manubrium in Fig. 4. In the rest position $[0 \mathrm{kPa}$, panel (a)], both sections of the eardrum are almost straight in their paths from the manubrium to the tympanic ring. Positive middle-ear pressures make both sections convex outward. When the pressure is returned to zero [panel (b)], the unpressurized shapes of both sections are now slightly convex outward and are somewhat different from the resting shapes measured at the beginning of the experiment. Small negative pressures straighten both sections, and extreme negative pressures make them concave. When the pressure is returned to zero after the negative excursion, both sections of the shape profile (not shown) are slightly concave and are again different from profiles previously measured at zero pressure. Similar patterns are seen in profiles for the other cats: anterior and posterior sections of the eardrum become increasingly convex outward with larger positive middle-ear pressures, but become straighter and finally concave with negative middle-ear pressure.

Displacements of the manubrium and pars tensa are asymmetric with respect to the sign of the applied pressure, with the lateral displacements caused by positive middle-ear pressures being larger than the medial displacements caused by negative pressures. The asymmetry appears to be more pronounced for the manubrium than for the pars tensa.

Figure 5 shows horizontal profiles through the manubrium of cat MY1216L, at the same location as profile 3 in Fig. 1. Panel (a) shows the response to positive middle-ear pressures during loading, whereas panel (b) shows the response to negative pressures. As mentioned above, the manubrium appears to be rigid and has smaller displacements su- periorly. The portion of the pars tensa inferior to the umbo in these profiles is convex outward in its resting position, and becomes even more curved when positive pressures are applied. Negative pressures reduce the curvature of this portion, but do not make the pars tensa concave or even straight in this area.

The pars flaccida, located superior to the manubrium, bulges considerably. In its initial state it is concave, but it becomes convex outward with positive pressures. The pars flaccida is sucked further into the middle-ear cavity when negative pressures are applied.

\section{Pressure-displacement curves}

Figure 6 shows how displacements for a typical point on the pars tensa vary with pressure and cycle for cat MY1216L. The point is located in the posterior pars tensa, and is indicated by the dot in Fig. 1. Eardrum response is nonlinear, with displacements growing less than in proportion to applied pressure, as seen by the $S$ shape of the pressure-displacement curves. For instance, the maximal displacement is $258 \mu \mathrm{m}$ at a pressure of $+1.1 \mathrm{kPA}$ during the first cycle while loading, whereas it is only $380 \mu \mathrm{m}$ at a pressure of $+2.2 \mathrm{kPA}$ during the same cycle. Although the pressure was doubled, the maximal displacement increased by a factor of only 1.38. As noted above, the response of the eardrum is asymmetric with respect to the sign of the applied pressure: lateral displacements caused by positive middle-ear pressures are larger than medial displacements caused by negative pressures. This is particularly noticeable at the extreme pressures. For example, the displacement magnitude is $380 \mu \mathrm{m}$ at a pressure of $+2.2 \mathrm{kPa}$ during the first cycle, whereas it is only $314 \mu \mathrm{m}$ at $-2.2 \mathrm{kPa}$ for the first cycle. The curves exhibit hysteresis, with displacements measured during unloading being larger than those measured during loading. The hysteresis seen here was also found by Dirckx 


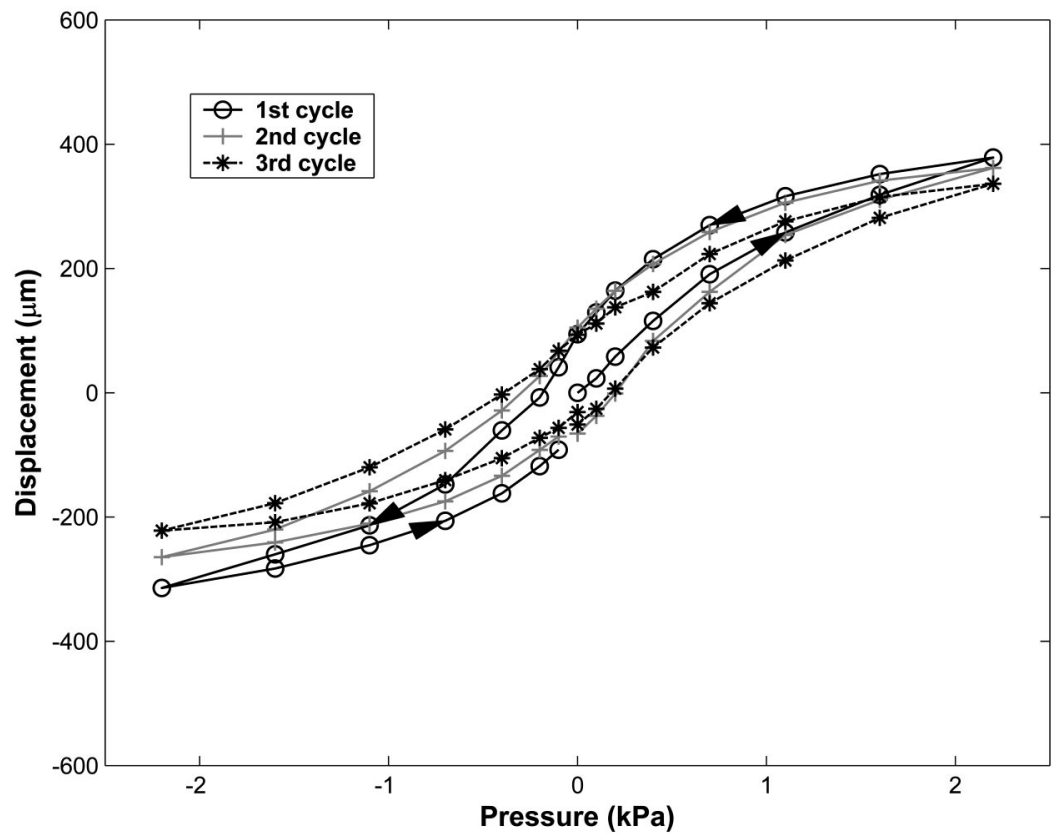

FIG. 6. Pressure-displacement curves for cat MY1216L taken through a point in the posterior pars tensa, for three cycles labeled with different symbols. The arrows indicate the temporal order of the measurements. Lateral displacements are positive, whereas medial displacements are negative.

and Decraemer (2001) in the gerbil. Displacement magnitudes also vary from cycle to cycle, generally decreasing from the first cycle to the last. In general, the behavior of soft tissue such as the eardrum depends upon its history, and the shape of the hysteretic force-displacement loop may change from one cycle to the next. If the material is taken through the same load cycle repeatedly, the force-displacement curve will normally converge to a stable shape; the material is said to have been "preconditioned" (Fung, 1993). Preconditioning has been observed in tympanometry (Gaihede, 1996). It is not clear whether the variations from cycle to cycle in the current study are due to gradual post-mortem changes or to the lack of a sufficient number of preconditioning cycles, or to a combination of both.

Pressure-displacement curves for the other cats are simi- lar except for differences in displacement magnitudes and in the degree of hysteresis. In cat MY1630L, displacements for negative pressures during unloading are, for the most part, smaller than during loading; the opposite is true in the other cats. In cat MY1721L, there is very little variation from one cycle to the next.

\section{B. Immobile malleus}

\section{Full-field displacement patterns}

Figure 7 is a gray-level displacement image for cat MY1216L for a pressure of $+2.2 \mathrm{kPa}$ for the first cycle of loading, with the malleus immobilized. Displacement images for other positive pressures are similar. (The displacement image is computed after registration.) With a fixed malleus,

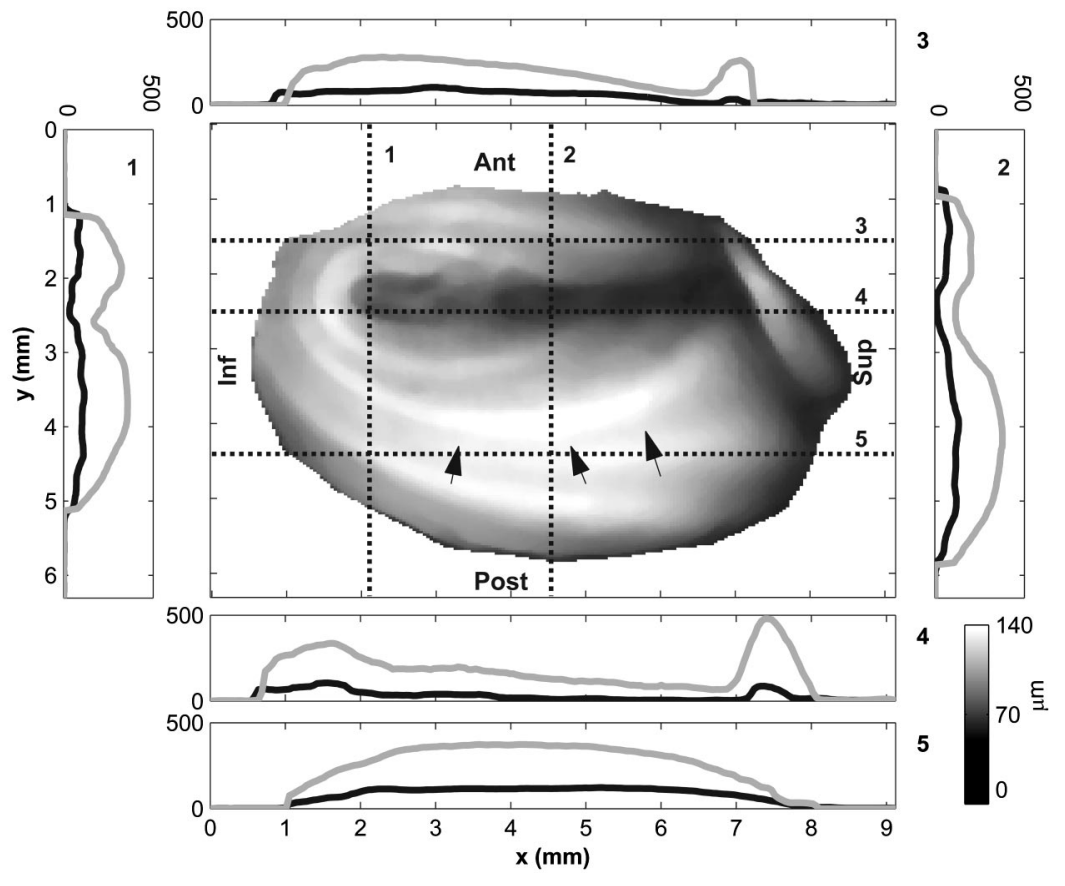

FIG. 7. Gray-level displacement image and profiles for cat MY1216L measured at a pressure of $+2.2 \mathrm{kPa}$ during the first cycle after immobilizing the malleus. Dotted lines indicate where the profiles are extracted from, with black profiles corresponding to the fixed-malleus data and gray profiles corresponding to the mobilemalleus data. Displacements indicated on the profiles are in $\mu \mathrm{m}$. The arrows indicate artifacts that show up as dark bands in bright regions of the displacement image; the arrows outline the path of one such band. 
TABLE I. Displacement of the pars flaccida before and after mallear fixation measured at a pressure of $+2.2 \mathrm{kPa}$ during the first cycle of pressurization.

\begin{tabular}{lccc}
\hline \hline & \multicolumn{3}{c}{ Displacement } \\
\cline { 2 - 4 } & Fixed $(\mu \mathrm{m})$ & Mobile $(\mu \mathrm{m})$ & Fixed/mobile \\
\hline MY1216L & 100 & 490 & $20 \%$ \\
MY1630L & 320 & 380 & $84 \%$ \\
MY0923R & 415 & 630 & $66 \%$ \\
\hline \hline
\end{tabular}

artifactual bands resembling iso-depth contours are visible, and show up as dips and peaks in the displacement profiles. The bands are the dark streaks in areas where the displacement image should be white. As an example, one of the bands is shown by arrows in Fig. 7. The bands are caused by very small systematic errors associated with the shapereconstruction algorithm used with the moire apparatus (Ladak et al., 2000). Although the errors are small and completely masked for the large displacements observed with a mobile malleus at high pressures, they are not completely masked for small displacements. The black profiles are for the fixed-malleus data, and the gray ones are for the mobilemalleus data. Profile 4 shows that the manubrium is immobile, or almost so, along most of its length. Profile 2 further illustrates that the manubrium is practically immobile superiorly, whereas profile 1 shows that the manubrium displaces slightly near the umbo.

For this cat, with a fixed malleus there is a broad displacement maximum in the posterior pars tensa with a magnitude of $140 \mu \mathrm{m}$; this value is about $37 \%$ of the corresponding maximum value for the mobile-malleus case. For cats MY1630L and MY0923R, the maximum pars-tensa displacements with fixed mallei were $52 \%$ and $46 \%$ of the mobilemalleus values, respectively.

The maximum pars-flaccida displacement for cat
MY1216L is $100 \mu \mathrm{m}$, which is only about $20 \%$ of the value for the mobile case. This is a surprisingly large decrease. For cats MY1630L and MY0923R, the maximum pars-flaccida displacements with fixed mallei were $84 \%$ and $66 \%$ of the mobile-malleus values, respectively. Table I lists maximal pars-flaccida displacements before and after mallear fixation, as well as the ratio of displacement after fixation to displacement in the mobile-malleus case.

Figure 8 shows fixed-malleus iso-amplitude displacement contours for all three cats. The difference in amplitude between adjacent contours is $25 \mu \mathrm{m}$. The patterns are somewhat distorted by the systematic errors discussed above. The patterns are qualitatively similar, although the pattern for cat MY0923R exhibits a strong maximum in the anterior pars tensa as well as in the posterior pars tensa. In cats MY1630L and MY0923R, the manubrium displaces more than in cat MY1216L. Examination of the specimens after the experiments indicated that the head of the malleus in each of these cats was indeed fixed to the middle-ear wall. However, it is possible for the manubrium to bend. The displacement of the umbo and of the superior end of the manubrium are tabulated in Table II for all three cats in which the malleus could be fixed. Ideally, if the manubrium is perfectly fixed, displacements along its length should be zero. For comparison, the displacement with a normal mobile malleus is also listed. The ratio of fixed/mobile displacement is a measure of the degree of manubrial fixation, with values closer to zero indicating more fixation relative to the mobile case. Results are reported for a pressure of $+2.2 \mathrm{kPa}$ because this represents an extreme case for which manubrial displacement would be largest. As can be seen, with a mobile malleus, the manubrium of cat MY0923R displaces more than that of cat MY1630L, and the manubrium of cat MY1630L displaces more than that of cat MY1216L except near the superior end. The same trend is observed in manubrial displacements after mallear fixation, with the manubrium of MY0923R displac-
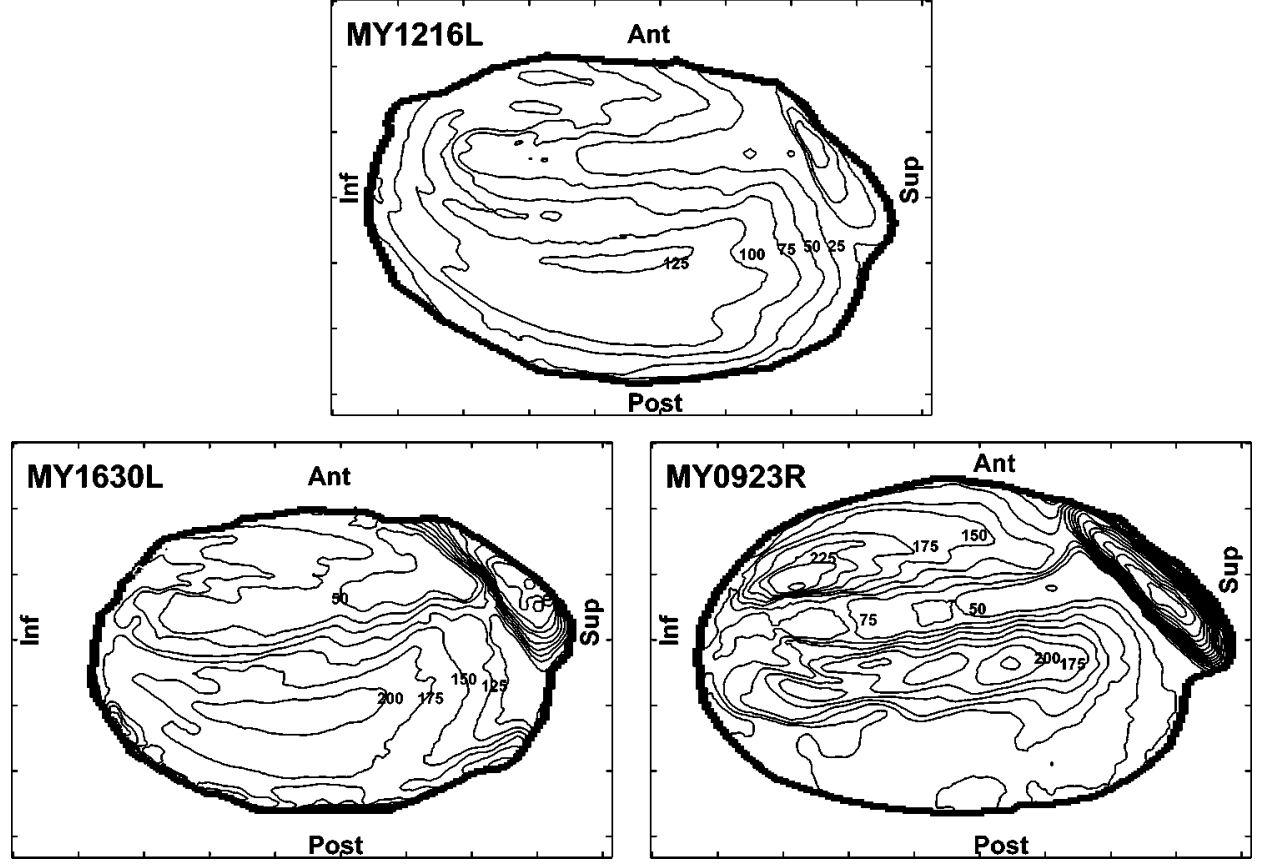

FIG. 8. Iso-amplitude displacement contours for all cats in which the malleus was immobilized. The data are for a pressure of $+2.2 \mathrm{kPa}$ during the first cycle. Displacements are in $\mu \mathrm{m}$, and adjacent contours are $25 \mu \mathrm{m}$ apart. Note that in cat MY0923R measurements were made on the right ear instead of the left ear as in the other cats. To facilitate comparison of MY0923R with the other cats, the image of the eardrum was mirrored to look like the others. 
TABLE II. Displacements of the umbo and superior end of manubrium before and after mallear fixation measured at a pressure of $+2.2 \mathrm{kPa}$ during the first cycle of pressurization.

\begin{tabular}{|c|c|c|c|c|c|c|}
\hline & \multicolumn{3}{|c|}{ Displacement at umbo } & \multicolumn{3}{|c|}{$\begin{array}{c}\text { Displacement at superior end of } \\
\text { manubrium }\end{array}$} \\
\hline & $\begin{array}{l}\text { Fixed } \\
(\mu \mathrm{m})\end{array}$ & $\begin{array}{l}\text { Mobile } \\
(\mu \mathrm{m})\end{array}$ & Fixed/mobile & $\begin{array}{c}\text { Fixed } \\
(\mu \mathrm{m})\end{array}$ & $\begin{array}{l}\text { Mobile } \\
(\mu \mathrm{m})\end{array}$ & Fixed/mobile \\
\hline MY1216L & 32 & 156 & $21 \%$ & 5 & 70 & $7 \%$ \\
\hline MY1630L & 54 & 181 & $30 \%$ & 10 & 60 & $17 \%$ \\
\hline MY0923R & 68 & 226 & $31 \%$ & 20 & 90 & $22 \%$ \\
\hline
\end{tabular}

ing more than that of MY1630L, which displaces more than that of MY1216L. The fixed/mobile ratio indicates that the manubrium of cat MY1216L is better fixed than that of cats MY1630L and MY0923R. Furthermore, the degree of manubrial fixation in cat MY1630L is greater than that in cat MY0923R at the superior end of the manubrium. Manubrial displacements with a fixed malleus are small and remain small during pressurization.

Displacement patterns for negative pressures in all cats except MY0923R are similar to those for positive pressures, but the location of the pars-tensa maximum is pushed slightly in the postero-inferior direction. In cat MY0923R, the displacement pattern becomes considerably simpler than that for positive pressures, and the location of maximum displacement occurs in the posterior pars tensa as opposed to the anterior pars tensa as it does for positive pressures in this cat.

\section{Pressurized shape profiles}

Figure 9 shows vertical profiles through the pressurized shape data for cat MY1216L after mallear fixation and registration to the mobile-malleus data. The profiles are taken at the same location as profile 2 in Fig. 1. For clarity, only profiles for pressures of 0 (very first measurement), \pm 1.1 and $\pm 2.2 \mathrm{kPa}$ are shown; the fixed-malleus profiles are in black. Superimposed in gray are corresponding profiles for pressures of $\pm 2.2 \mathrm{kPa}$ for the mobile-malleus case. The sections of the pars tensa both anterior and posterior to the manubrium in these profiles are convex outward at rest and the curvature increases with positive middle-ear pressures. Negative pressures straighten both sections, but in the fixedmalleus case do not make them concave in this particular cat. In the other cats, extreme negative pressures do make both sections of the pars tensa slightly concave in vertical profiles extracted at the same location, but the change in shape is not as dramatic as with a mobile malleus.

\section{Pressure-displacement curves}

With a fixed malleus, the pressure-displacement curves that were obtained vary considerably from cat to cat, and are described individually here. Figure 10(a) is a pressuredisplacement curve for cat MY1216L; the curve is for the same point as that shown in Fig. 1 by the dot. The curves show the same general features as those for the mobilemalleus data. During the first cycle, displacements increase less than in proportion to the applied pressure. For example, when the pressure is doubled from +1.1 to $+2.2 \mathrm{kPa}$, the displacement increases by only 1.6 times. Nonlinearity is more pronounced for the unloading branch than for the loading branch. Displacements for the next two cycles are smaller than for the first cycle, and the loading branches appear to be almost linear.

Figure 10(b) shows pressure-displacement curves for cat MY1630L. Nonlinearity is more pronounced in this cat. Displacement magnitudes for the first two cycles and the positive part of the third cycle are similar, but for the negative part of the third cycle the displacement magnitudes are much smaller than for the other cycles. It is not clear why the third cycle is so different; there was no leakage in the pressurization apparatus.

Figure 10(c) shows the same curves for cat MY0923R. In this cat, displacements vary considerably from cycle to cycle. The first cycle is very different from the second and third, which are quite similar. During the first cycle, medial

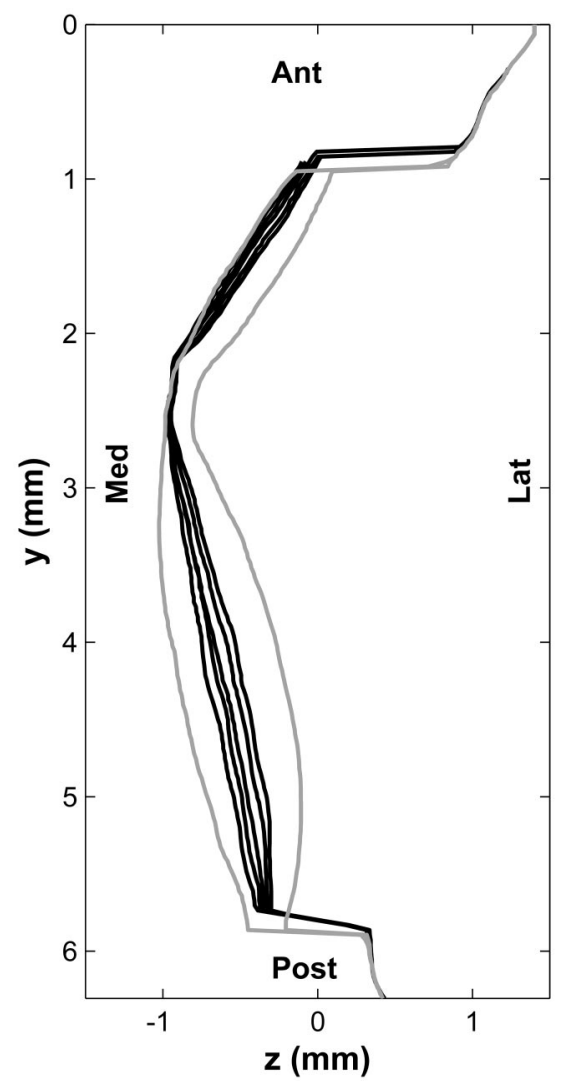

FIG. 9. Vertical profiles through pressurized shape data for cat MY1216L. Fixed-malleus (black) and mobile-malleus (gray) data are shown after registration. The profiles are taken through a point halfway up the manubrium. 

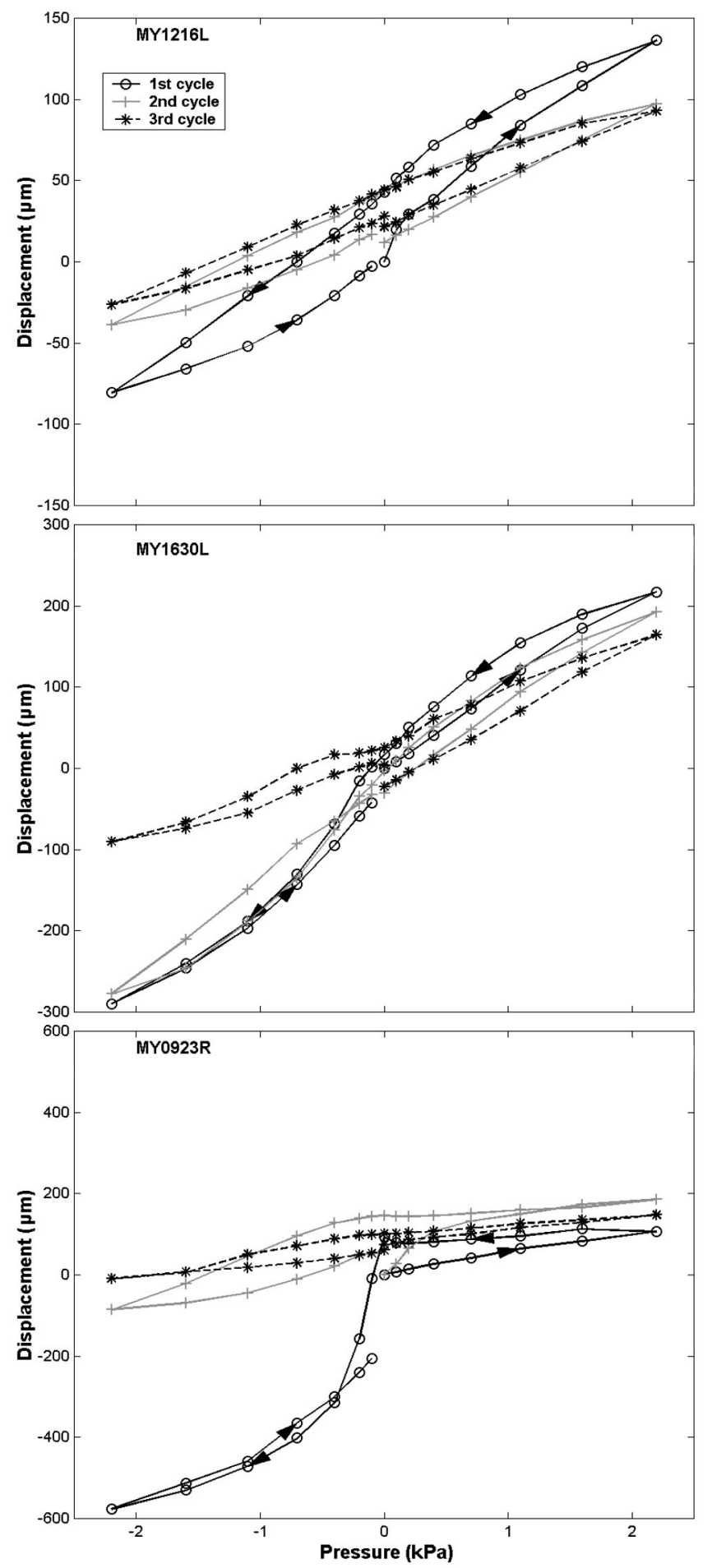

FIG. 10. Pressure-displacement curves for cats MY1216L, MY1630L, and MY0923R after mallear fixation for a point in the posterior pars tensa. The arrows indicate the temporal order of the measurements. Lateral displacements are positive, whereas medial displacements are negative.

displacements in response to negative middle-ear pressures are much larger than lateral displacements due to positive pressures. After the negative excursion, the eardrum does not return to its original shape, and the unpressurized shape measured at the beginning of the second cycle is considerably different from that measured at the beginning of the experiment.

\section{Effects of measurement time}

In cat MY1721L, the malleus was not fixed. Instead, the response to a sequence of three cycles was first measured and then, after a wait of $2 \mathrm{~h}$ (which was the longest time required to fix the malleus in the other specimens), the response to another three cycles was measured. This specimen serves as a control to test what effects, if any, measurement time and mallear-fixation time have on the response. Figure 11 shows pressure-displacement curves for a typical point on the pars tensa; the black curve is for the first set of three measurements, whereas the gray one is for the second set. As the responses were similar from one cycle to the next in any one set of measurements for this cat, all three cycles for one set of measurements were averaged in order to simplify the graph. Displacements measured during the second sequence of loading are generally smaller than those measured during the first sequence. The largest difference in displacement magnitude over the entire surface of the pars tensa is less than $50 \mu \mathrm{m}$ and occurs at the highest pressures. This value is much smaller than the difference seen after malleus fixation, implying that measurement and fixation times have only a small effect on eardrum behavior. For comparison, the largest difference in pars-tensa displacement after mallear fixation and at a pressure of $+2.2 \mathrm{kPa}$ (first cycle) was $240 \mu \mathrm{m}$ for cat MY1216L, $225 \mu \mathrm{m}$ for cat MY1630L, and $325 \mu \mathrm{m}$ for cat MY0923R.

\section{DISCUSSION}

The displacement patterns previously measured in response to large static pressures in cats (Stoffels, 1993), humans (Dirckx and Decraemer, 1991), and gerbils (von Unge et al., 1993; Dirckx and Decraemer, 2001), with a normal mobile malleus, are similar in that the pars-tensa displacements are always larger than manubrial displacements, with the largest pars-tensa displacements generally occurring in the posterior region rather than in the anterior region. With the exception of one cat (MY0923R), the displacement patterns measured in this work are similar to those measured previously. Modeling studies indicate that eardrum response is sensitive to variations in shape, stiffness, and thickness (e.g., Funnell and Laszlo, 1978), each of which may vary not only among cats but also spatially across the surface of the eardrum in any particular cat. Finite-element calculations utilizing subject-specific shape information for cat MY0923R indicated that local variations in shape do not alone account for all of the differences between displacement patterns for cat MY0923R and the other cats (Ladak, 1998). Furthermore, there were no visible localized differences in thickness. It is quite plausible that the local stiffness of the anterior pars tensa in this cat was lower than that of the posterior pars tensa, resulting in larger displacements in the anterior region.

This is the first time that complete loading and unloading cycles have been measured in cats. The observed pressure-displacement curves indicate that eardrum response is not elastic, i.e., the original shape of the eardrum is not restored when loads are removed. The eardrum, like many other tissues, is viscoelastic (Decraemer et al., 1980). The 


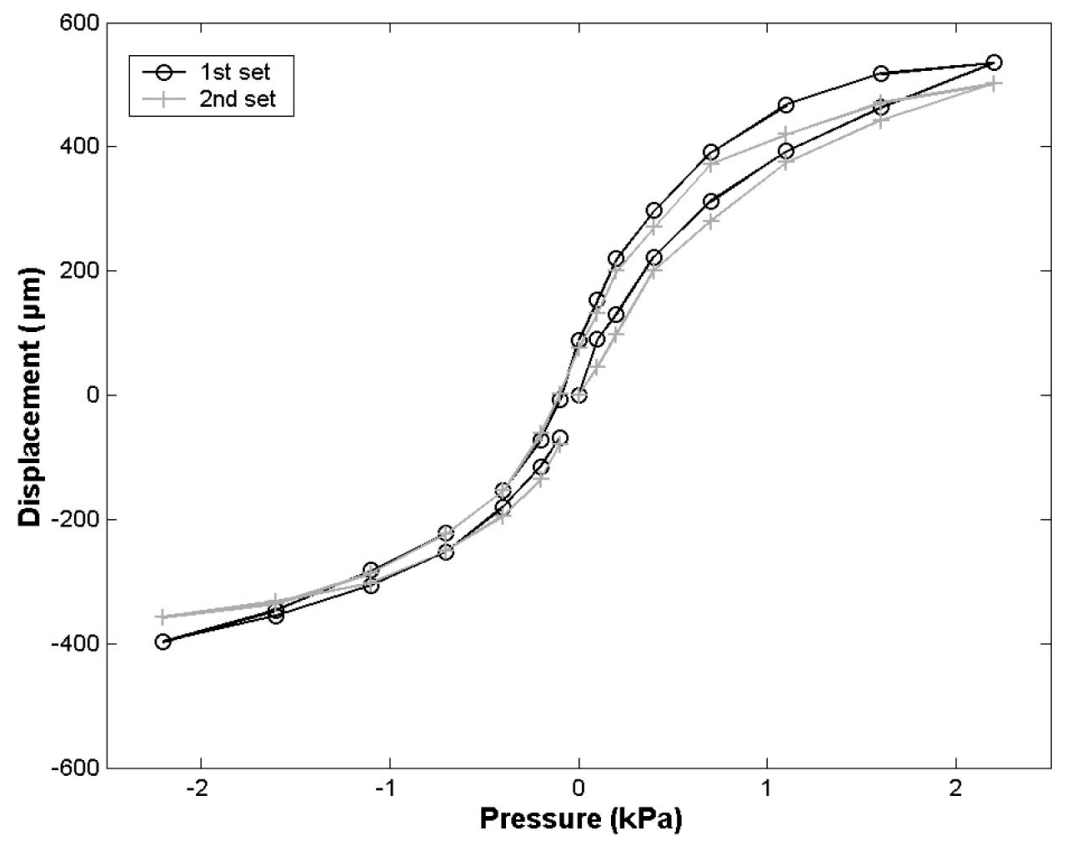

FIG. 11. Averaged pressure-displacement curves for cat MY1721L taken through a point in the posterior pars tensa. The second set was taken $2 \mathrm{~h}$ after the first set. Each set consists of three cycles averaged together. Lateral displacements are positive, whereas medial displacements are negative.

multiple loading/unloading cycles measured in each eardrum in this work are more repeatable than those measured previously in cats (Stoffels, 1993) because a stricter schedule and protocol were followed for the measurements reported here. The response of soft tissues generally depends on their loading/unloading histories. Indeed, in clinical tympanometry differences in measurement protocol do result in pronounced differences in tympanometric data (Osguthorpe and Lam, 1981).

With a mobile malleus, eardrum response is complicated by the mechanical load exerted on it by the rest of the middle ear. For instance, at high pressure levels, ossicular response in humans is known to be asymmetric and nonlinear (Hüttenbrink, 1989), which in turn affects eardrum response. Asymmetry in ossicular displacements at high pressures has been said to arise from slippage in the joints between the malleus and the incus and between the incus and the stapes (Guinan and Peake, 1967; Cancura, 1980; Hüttenbrink, 1989; Decraemer et al., 2003) — the joints are easily stretched by large positive middle-ear pressures but are only slightly compressed by negative pressures. Another source of nonlinearity in the ossicular response may be the annular ligament connecting the stapes to the oval window, which limits the displacement of the stapes (Price, 1974; Price and Kalb, 1986; Pascal et al., 1998); indeed, Price and Kalb (1991) feel that this is the main source of nonlinearity in middle-ear response at high pressures.

In order to characterize the behavior of the eardrum independently of the ossicular chain, experiments with an immobile malleus were conducted. This permits comparison with a finite-element model of the eardrum, for example, without the complication of a complete middle-ear model. With an immobile malleus, pars-tensa displacements decrease because of the decreased mobility of the manubrium. Even with an immobile malleus, the eardrum response is seen to exhibit features such as nonlinearity, asymmetry and hysteresis, although the degree of nonlinearity is somewhat reduced. There are considerable differences in pressure- displacement curves measured among the three cats, which could reflect interindividual differences in shape, stiffness, and thickness. The eardrum displacements reported here for large static pressures after mallear fixation are several times larger than the thickness of the eardrum; this suggests that, at the very least, geometric nonlinearities must be taken into account in constructing finite-element models of the eardrum that are valid at high pressures (Ladak and Funnell, 1995). It may also be necessary to consider nonlinearities of material properties. In any case, it appears that eardrum nonlinearity cannot be completely ignored in comparison with nonlinearities arising from other middle-ear structures, as has been assumed by previous investigators (Price and Kalb, 1991; Wada and Kobayashi, 1990).

With reference to Figs. 7 and 8 and Table II, it is clear that the technique used to render the malleus immobile does not result in every point on the manubrium having exactly zero displacement. Although the point on the mallear head that is glued to the middle-ear wall remains fixed, the manubrium appears to bend. The apparent bending of the manubrium observed here may be consistent with the manubrial bending discussed by Funnell et al. (1992) and Decraemer et al. (1994), although it is difficult to quantitatively compare that bending, in the linear regime at frequencies of $2 \mathrm{kHz}$ and higher, with the present relatively low-resolution static measurements in the nonlinear regime. The 1992 and 1994 results suggested that there is likely to be less bending at lower frequencies, which is consistent with the fact that pronounced bending is not seen in the present measurements.

Displacement patterns for the pars flaccida are qualitatively similar before and after mallear fixation and between individuals. However, there is considerable interindividual variability in the size of the displacements both before and after mallear fixation. In all cases, displacement magnitude decreases after mallear fixation, but the degree of decrease as indicated by the fixed/mobile ratio in Table I exhibits interindividual differences. Variability in this decrease may be related to individual differences in the properties of the pars 
flaccida or to the degree of manubrial fixation. One might expect that the greater the degree of manubrial fixation is, the greater the decrease in pars-flaccida displacement will be after fixation. Note that in cat MY1216L the decrease in parsflaccida displacement is dramatic, as is the decrease in manubrial displacements, particularly at the superior end. In cats MY1630L and MY0923R, the degree of decrease in manubrial displacement is not as large as in cat MY1216L, and neither is the degree of decrease in pars-flaccida displacements. However, the relationship between degree of mallear fixation and pars-flaccida mobility is not clear from these data since in cat MY1630L the malleus is less mobile after fixation than in cat MY0923R, while the degree of decrease of pars-flaccida displacement in cat MY1630L is lower than that of cat MY0923R. Experiments in the same animal in which the degree of manubrial fixation is varied would certainly help address whether the variability in the degree of decrease in pars-flaccida displacement is related to the degree of manubrial fixation.

\section{CONCLUSION}

In this study, the shape of the cat eardrum was measured with a normal mobile malleus and an immobile malleus during cyclical loading with static middle-ear pressures up to $\pm 2.2 \mathrm{kPa}$. The shape was monitored throughout the loading and unloading phases, and three complete cycles were observed. The use of a coarse grating, to complement the fine grating used for most of the measurements, was shown to permit resolution of the phase ambiguities of the moire technique at locations where the bony ear canal overhangs the eardrum.

Displacement patterns with a mobile malleus show that pars-tensa displacements are larger than manubrial displacements, as expected, with the maximum pars-tensa displacement occurring in the posterior region in all cats except one. For both the mobile-malleus and immobile-malleus cases, the eardrum response is nonlinear with displacements growing less than in proportion to applied pressure. Moreover, the response is asymmetric, with lateral displacements (caused by positive middle-ear pressures) being larger than medial displacements. With a mobile malleus, manubrial displacements exhibit more pronounced asymmetry than pars-tensa displacements. In both cases, displacement magnitudes vary from cycle to cycle.

Considerable variability was observed in the responses to negative pressures. The eardrum shape may change from being convex outward to being concave. The erratic results for negative pressures might be due to a mechanical instability such as snap-through buckling of the eardrum. This is a form of instability in which a sudden jump from one equilibrium configuration to a very different equilibrium configuration occurs at a specific pressure, and is observed as a local reversal in curvature. As mentioned previously, eardrum mechanical response is sensitive to shape changes, and the sudden shape changes associated with snap-through buckling could produce a drastically different displacement when the pressure is changed than would be expected if snap-through did not occur.
Although the results presented here (e.g., Fig. 11) indicate that the underlying mechanical properties of the eardrum did not necessarily change much during the course of the experiment, more work is required to clarify the roles of variability, preconditioning, and post-mortem effects.

This work provides a basis for constructing and validating models of the nonlinear response of the eardrum in response to large static pressures. Beyond that, it will contribute to the interpretation of measurements of the response of the entire middle ear to large static pressures (Decraemer et al., 2003) and ultimately to the detailed modeling of the mechanics and acoustics of tympanometry. Once nonlinear models such as that proposed by Ladak and Funnell (1995) are validated using the data measured in this work, such models can, in principle, be used to simulate any loading pattern, including static pressure applied to the lateral side of the eardrum as in tympanometry. Furthermore, by including inertial and damping effects in such models, it would be possible to simulate the response to sinusoidal tones superimposed on static pressures as in tympanometry.

\section{ACKNOWLEDGMENTS}

Funding for this work was provided through an operating grant from the Canadian Institutes of Health Research (W.R.J.F.), and through fellowships from the Natural Sciences and Engineering Research Council of Canada (H.M.L.) and the Québec-Belgium Exchange Program (H.M.L.). We thank J. Lauzière for editing the manuscript.

\section{DEDICATION}

This paper is dedicated in memory of Amina Ladak, Maurice B. Decraemer and L. Grace Funnell.

Besl, P. J., and McKay, N. D. (1992). "A method for registration of 3-D shapes,” IEEE Trans. Pattern Anal. Mach. Intell. 14, 239-256.

Cancura, W. (1980). "On the statics of malleus and incus and on the function of the malleus-incus joint," Acta Oto-Laryngol. 89, 342-344.

Dahmann, H. (1930). "On the physiology of hearing: Experimental studies on the mechanics of the ossicular chain, as well as on the behaviours of tones and air pressure II-IV," Zeitschr. f. Hals. Nas. Ohrenheilkd. 27, 329-368.

Decraemer, W. F., and Dirckx J. J. J. (1991). "Moiré-shift interferometer measurements of the shape of human and cat tympanic membrane," Proc. SPIE Vol. 1429, Holography, Interferometry, and Optical Pattern Recognition in Biomedicine, 26-33.

Decraemer, W. F., Maes, M. A., Vanhuyse, V. J., and Vanpeperstraete, P. (1980). "A non-linear viscoelastic constitutive equation for soft biological tissues based upon a structural model," J. Biomech. 13, 559-564.

Decraemer, W. F., Dirckx, J. J. J., and Funnell, W. R. J. (1991). "Shape and derived geometrical parameters of the adult, human tympanic membrane measured with a phase-shift moiré interferometer," Hear. Res. 51, 107122.

Decraemer, W. F., Khanna, S. M., and Funnell, W. R. J. (1994). "Bending of the manubrium in cat under normal sound stimulation," SPIE Proc. 2329, $74-84$.

Decraemer, W. F., Gea, S. L. R., and Dirckx, J. J. J. (2003). "Threedimensional displacement of the gerbil ossicular chain under static pressure changes," 26th Midwinter Research Meeting of the Association for Research in Otolaryngology, Abstract \#975 (ARO Web site).

Dirckx, J. J. J., Decraemer, W. F., and Dielis, G. (1988). "Phase shift method based on object translation for full field automatic 3-D surface reconstruction from moiré topograms," Appl. Opt. 27, 1164-1169.

Dirckx, J. J. J., and Decraemer, W. F. (1989). "Phase shift moiré apparatus for automatic 3-D surface measurement," Rev. Sci. Instrum. 60, 36983701. 
Dirckx, J. J. J. (1990). "Automated moiré topography and its applications for shape and deformation measurements of the tympanic membrane," Ph.D. thesis, University of Antwerp, UIA, November 1990.

Dirckx, J. J. J., and Decraemer, W. F. (1990). "Automatic calibration method for phase shift shadow moiré interferometry," Appl. Opt. 29, $1474-1476$.

Dirckx, J. J. J., and Decraemer, W. F. (1991). "Human tympanic membrane deformation under static pressure," Hear. Res. 51, 93-105.

Dirckx, J. J. J., and Decraemer, W. F. (1997). "Coating techniques in optical metrology," Appl. Opt. 36, 2776-2782.

Dirckx, J. J. J., Decraemer, W. F., von Unge, M., and Larsson, Ch. (1998).

"Volume displacement of the gerbil eardrum pars flaccida as a function of middle ear pressure," Hear. Res. 118, 35-45.

Dirckx, J. J. J., and Decraemer, W. F. (2001). "Effect of middle ear components on eardrum quasi-static deformation," Hear. Res. 157, 124-137.

Fung, Y. C. (1993). Biomechanics: Mechanical Properties of Living Tissues, 2nd ed. (Springer, New York).

Funnell, W. R. J., and Decraemer, W. F. (1996). "On the incorporation of moire shape measurements in finite-element models of the cat eardrum," J. Acoust. Soc. Am. 100, 925-932.

Funnell, W. R. J., and Laszlo, C. A. (1978). "Modeling of the cat eardrum as a thin shell using the finite-element method," J. Acoust. Soc. Am. 63, $1461-1467$.

Funnell, W. R. J., Khanna, S. M., and Decraemer, W. F. (1992). "On the degree of rigidity of the manubrium in a finite-element model of the cat eardrum," J. Acoust. Soc. Am. 91, 2082-2090.

Gaihede, M. (1996). "Tympanometric preconditioning of the tympanic membrane," Hear. Res. 102, 28-34.

Guinan, Jr., J. J., and Peake, W. T. (1967). "Middle-ear characteristics of anesthetized cats,” J. Acoust. Soc. Am. 41, 1237-1261.

Horn, B. K. P. (1987). "Closed-form solution of absolute orientation using unit quaternions,” J. Opt. Soc. Am. A 4, 629-642.

Hüttenbrink, K. N. (1989). "The mechanics of the middle ear at static air pressures," Acta Otolaryngol. (Stockh.) Suppl. 451, 1-35.

Kessel, J. (1874). "On the influence of the middle-ear muscles on the displacements and vibrations of the eardrum in the cadaver ear," Arch. Ohrenheilkd. 8, 80-92 (in German).

Ladak, H. M. (1998). "Finite-element and experimental analyses of the response of the cat eardrum to large static pressures," Ph.D. thesis, McGill University, Montréal.

Ladak, H. M., and Funnell, W. R. J. (1995). "On the effects of geometric nonlinearities in a finite-element model of the cat eardrum," Proc. IEEE Engineering in Medicine \& Biology Society 17th Annual Conference and 21st Canadian Medical \& Biological Engineering Conference, Montreal, QC, pp. 1439-1440.

Ladak, H. M., Decraemer, W. F., Dirckx, J. J. J., and Funnell, W. R. J. (2000). "Systematic errors in small deformations measured using shadowmoiré topography,” Appl. Opt. 39, 3266-3275.
Margolis, R. H., Osguthorpe, J. D., and Popelka, G. R. (1978). "The effects of experimentally-produced middle ear lesions on tympanometry in cats," Acta Oto-Laryngol. 86, 428-436.

Naito, Y. (1990). "Holographic observation of the tympanic membrane vibration after stapes fixation,” Nippon Jibi Inkoka Gakkai Kaiho 93, 2021 2027.

Osguthorpe, J. D., and Lam, C. (1981). "Methodologic aspects of tympanometry in cats," Otolaryngol.-Head Neck Surg. 89, 1037-1040.

Parnes, S. M., Cacace, A. T., Castracane, J., Conerty, M., and Gardner, G. M. (1996). "Advances in the development of the interferometric otoscope," Laryngoscope 106, 263-267.

Pascal, J., Bourgeade, A., Lagier, M., and Legros, C. (1998). "Linear and nonlinear model of the human middle ear," J. Acoust. Soc. Am. 104, 1509-1516.

Price, G. R. (1974). "Upper limit to stapes displacement: Implications for hearing loss," J. Acoust. Soc. Am. 56, 195-197.

Price, G. R., and Kalb, J. T. (1986). "Mathematical model of the effect of limited stapes displacement on hazard from intense sounds," J. Acoust. Soc. Am. Suppl. 1 80, S122.

Price, G. R., and Kalb, J. T. (1991). "Insights into hazards from intense impulses from a mathematical model of the ear," J. Acoust. Soc. Am. 90, 219-227.

Stoffels, E. J. A. J. (1993). "Geautomatiseerde moiré topografie, en zijn toepassing voor vorm-, vervormings- en diktemetingen aan het kattetrommelvlies" (Automated moiré topography and its application to shape, deformation and thickness measurements of the cat eardrum), Unpublished report of a period of practical training, Hogeschool Eindhoven, Faculty of Technics, Technical Physics (in Dutch).

Tonndorf, J., and Khanna, S. M. (1972). "Tumpanic-membrane vibrations in human cadaver ears studied by time-averaged holography," J. Acoust. Soc. Am. 52, 1221-1233.

von Unge, M., Borg, E., and Bagger-Sjöbäck, D. (1991). "Mechanoacoustic properties of the tympanic membrane: A study on isolated Mongolian gerbil temporal bones," Am. J. Otol. 12, 407-419.

von Unge, M., Decraemer, W. F., Bagger-Sjöbäck, D., and Dirckx, J. J. J. (1993). "Displacement of the gerbil tympanic membrane under static pressure variations measured with a real-time differential moiré interferometer," Hear. Res. 70, 229-242.

von Unge, M., Decraemer, W. F., Dirckx, J. J. J., and Bagger-Sjöback, D. (1999). "Tympanic membrane displacement patterns in experimental cholesteatoma," Hear. Res. 128, 1-15.

Vorwerk, U., Steinicke, G., and Begall, K. (1999). "Observation of eardrum movements during quasi-static pressure changes by high-speed digital imaging," Audiol. Neuro-Otol. 4, 150-155.

Wada, H., and Kobayashi, T. (1990). "Dynamical behaviour of middle ear: Theoretical study corresponding to measurement results obtained by a newly developed measuring apparatus," J. Acoust. Soc. Am. 87, 237-245.

Zhao, H., Chen, W., and Tan, Y. (1994). "Phase-unwrapping algorithm for the measurement of three-dimensional object shapes," Appl. Opt. 33, $4497-4500$. 